\title{
Comparative Evaluation of Diagnostic Performance of Circulating free DNA by Conventional vs. Real Time PCR in Gallbladder Cancer
}

\author{
Swati Kumari PhD ${ }^{1}$, Sridhar Mishra PhD ${ }^{1}$, Akash Agarwal MD ${ }^{2}$, Anshuman Pandey MD ${ }^{3}$, \\ Abhinav Sonkar MD ${ }^{4}$, Nuzhat Husain MD ${ }^{* 1}$ \\ ${ }^{1}$ Department of Pathology, Dr. Ram Manohar Lohia Institute of Medical Sciences, Vibhuti Khand, Gomti Nagar, \\ Lucknow, Uttar Pradesh, India \\ ${ }^{2}$ Department of Surgical Oncology, Dr. Ram Manohar Lohia Institute of Medical Sciences, Vibhuti Khand, Gomti \\ Nagar, Lucknow, Uttar Pradesh, India \\ ${ }^{3}$ Department of Gastro Surgery, Dr. Ram Manohar Lohia Institute of Medical Sciences, Vibhuti Khand, Gomti Nagar, \\ Lucknow, Uttar Pradesh, India \\ ${ }^{4}$ Department of Surgical Oncology, King Georges Medical University, Lucknow, Uttar Pradesh, India
}

*Corresponding author: Prof. Nuzhat Husain; drnuzhathusain@hotmail.com

Received 07 December 2021;

Accepted 25 December 2021;

Published 01 January 2022

\begin{abstract}
Background: Circulating free DNA (cfDNA) in serum/plasma has been studied as a promising biomarker in various pathologies, including cancer. However, there is no standardized method for the isolation and quantification of serum cfDNA. An effective and reliable method for isolation and quantification is of utmost importance before any clinical decision. The current study compares the conventional and real-time PCR methods to find any differences and concordance in cfDNA levels between the two methods and the diagnostic accuracy of cfDNA by each method. Methods: Serum sample was collected from 67 subjects, including 17 normal healthy individuals (control, $\mathrm{n}=17$ ), 19 disease controls (cholecystitis, $\mathrm{n}=19$ ), and 31 Gallbladder cancer patients (cancer, $\mathrm{n}=31$ ) before any treatment for cfDNA quantification. Results: The cfDNA level did not differ significantly between two methods in both control and cholecystitis groups. In cancer group, cfDNA level was significantly $(\mathrm{P}<0.001)$ different and higher in real time PCR as compared to conventional PCR. There was no significant correlation between two methods in control $(r=0.02, P=0.937)$, cholecystitis $(r=0.10, P=0.697)$, cancer $(r=-0.08, P=0.657)$ and total cases (control + cholecystitis + cancer $)$ $(\mathrm{r}=0.06, \mathrm{P}=0.622)$. The diagnostic accuracy of two methods was found similar $(\mathrm{P}>0.05)$ when assessed between control vs. cholecystitis $(\mathrm{Z}=0.85, \mathrm{P}=0.397)$, and control vs. total cases $(\mathrm{Z}=1.35, \mathrm{P}=0.177)$. However, the diagnostic accuracy of real time PCR was found significantly different and higher as compared to conventional PCR when assessed between control vs. cancer $(\mathrm{Z}=2.98, \mathrm{P}=0.003)$, and cholecystitis vs. cancer $(\mathrm{Z}=4.41, \mathrm{P}<0.001)$. Conclusion: Quantitative real-time PCR method is of high accuracy, reproducibility, and time-effectiveness. The diagnostic accuracy of real-time PCR was higher compared to conventional PCR.
\end{abstract}

Keywords: Circulating free DNA, Gallbladder cancer, Real-time PCR, Semi-quantitative PCR, cfDNA mutation.

\section{Introduction}

The presence of circulating free DNA (cfDNA) in blood was reported about 60 years ago ${ }^{[1]}$. Estimation of cfDNA opened up existing possibilities for non-invasive diagnostic evaluation of various malignant cancers and non-malignant pathological conditions like myocardial infarction, stroke, trauma, autoimmune disorders, and chronic inflammation. CfDNA serves as a noninvasive biomarker for molecular analysis in pre-cancer \& cancer, and quantification may help optimize medical practice, personalized medicine and improve quality of life ${ }^{[2,3]}$. The presence of cfDNA has been reported in serum, plasma, induced sputum, bronchial lavage, milk, urine, and stool ${ }^{[4]}$. Release of cfDNA in circulation occurs via active release from diseased cells, apoptosis and necrosis, and the interface of the tumor $\&$ adjacent non-tumor cells; however, its release into the circulation is still debated ${ }^{[2,5-6]}$.

Increased levels of cfDNA have been reported in lung ${ }^{[7]}$, breast $^{[8]}$, bladder ${ }^{[9]}$, prostate ${ }^{[10]}$, gastric ${ }^{[11]}$, colon ${ }^{[12]}$, cervical ${ }^{[13]}$, ovarian ${ }^{[14]}$, testis ${ }^{[15]}$ and hepatocellular cancer ${ }^{[16]}$. The 
standardization of extraction methodology, sample be used serum vs. plasma and normal ranges in children, adults need to be established. CfDNA has found application as a diagnostic marker and detecting tumor markers to initiate or modify targeted therapy. CfDNA has also been known to increase inflammatory and other non-malignant conditions, and to make this distinction in cfDNA of either origin is another critical issue ${ }^{[17]}$.

Various methods exist for isolation and quantification of cfDNA from Serum/Plasma but still need to be optimized for accuracy, repeatability, reliability, sensitivity, and specificity. With the development of PCR and quantitative PCR techniques, understanding of cfDNA is rapidly growing. However, radioimmunoassay ${ }^{[18]}$, DNA Dip Stick-TM Kit, Pico Green assay ${ }^{[19]}$, direct nick translation DNA labelling ${ }^{[20]}$, and spectrophotometry ${ }^{[21]}$ have also reported significantly increased concentration of cfDNA in plasma/serum of cancer patients. Since cfDNA analysis may serve as a liquid biopsy in several malignancies, selecting a consistent and efficient serum/plasma cfDNA quantification method would be important before estimating cfDNA in cancer patients.

As Radioimmunoassay (P32) and UV-based spectrophotometers cannot detect cfDNA concentration below the range of nanograms, quantitative real-time PCR is considered a standard technique but still requires precise automated systems stays expensive. We have attempted to compare conventional and real-time PCR to find any differences and concordance in cfDNA between the two methods and diagnostic accuracy (sensitivity and specificity) of cfDNA to discriminate controls and cases by each method.

\section{Material and Methods}

\section{Patient selection}

The quantification of cfDNA level was done in a total of 67 subjects, including 17 normal healthy individuals (control, $n=17$ ), 19 disease controls (cholecystitis, $\mathrm{n}=19$ ), and 31 gallbladder cancer patients (cancer, $n=31$ ) using conventional PCR and real-time PCR. The cfDNA level was measured in nanogram per millilitre (ng/ml). All the patients who fulfilled the inclusion criteria were recruited for the study. Written informed consent was taken from the patients. Ethical clearance was obtained from Institutional Ethical Committee. Participants were excluded from the study if they had undergone previous chemotherapy/radiotherapy, those with evidence of significant other clinical disorders and pregnant or breastfeeding women in control samples, or individuals not willing to participate.

\section{Blood collection and Serum DNA extraction}

$4.00 \mathrm{ml}$ of peripheral blood was collected from cases and controls before surgery or treatment in silica gel vials (B. D. Biosciences, USA). Serum was separated by centrifugation at $1800 \mathrm{xg}$ for 10 min. Followed by high-speed centrifugation at $16000 \mathrm{~g}$ for $10 \mathrm{~min}$ and stored at $-80^{\circ} \mathrm{C}$ until further processing. All samples were processed within 1 hour of collection to avoid potential contamination of leukocytes.

As per the manufacturer's instructions, serum cfDNA was extracted by Charge Switch ${ }^{\circledR}$ gDNA $1 \mathrm{~mL}$ Serum Kit (Invitrogen, USA) ${ }^{[22]}$. Purified cfDNA was stored at $-80^{\circ} \mathrm{C}$ for further processing. The $\beta$-globin gene primer was used in both semiquantitative and quantitative real-time PCR ${ }^{[23]}$.

Quantification of cfDNA levels by semi-quantitative polymerase chain reaction (PCR): Semi-quantitative conventional PCR was performed in $20 \mu$ reaction volume per sample containing $2 \mu \mathrm{l}$ of cfDNA, $2 \mu \mathrm{l}$ of $10 \mathrm{X}$ PCR buffer (Invitrogen, USA), $0.5 \mu \mathrm{l}$ of $10 \mathrm{mM}$ dNTPs (BR-Biochem, India), $1 \mu \mathrm{l}$ of 10pmoles of forward and reverse primers each (Eurofins Bangalore, India), $0.8 \mu \mathrm{l}$ of $25 \mathrm{mM} \mathrm{MgCl} 2$ (Invitrogen, USA), $0.4 \mu \mathrm{l}$ $(5 \mathrm{U} / \mu \mathrm{l})$ of Taq polymerase (Invitrogen, USA) and the volume was brought to $20 \mu \mathrm{l}$ by nuclease water. The thermal profile of the PCR was started with an initial denaturation at $94^{\circ} \mathrm{C}$ for $9 \mathrm{~min}, 35$ cycles of $1 \mathrm{~min}$ at $95^{\circ} \mathrm{C}, 1 \mathrm{~min}$ at $55^{\circ} \mathrm{C}$, and $1 \mathrm{~min}$, the final extension of 5 min at $72^{\circ} \mathrm{C}$. The amplified PCR amplicons were checked for $268 \mathrm{bp}$ product on $2 \%$ agarose gel by ethidium bromide staining (Figure 1a). The intensity of the $\beta$ globin PCR product on agarose gel (representative of the amount of cfDNA) was quantified by Image $\mathrm{J}$ software (NIH, USA). Mean intensity was calculated by dividing the background intensity from the $\beta$-globin intensity. All measuring parameter of Image $\mathbf{J}$ was constant for the measurement of intensity.

\section{Quantification of cfDNA levels by real-time quantitative PCR (QPCR)}

CfDNA quantification in cases and controls was also quantified by quantitative SYBR Green real-time PCR (QPCR) and compared with standard curve plotted by TaqMan control human genomic DNA at $10 \mathrm{ng} / \mathrm{ml}$ (Applied Biosystem, USA). QPCR was performed on the CFX96 Real-Time PCR system (Bio-Rad Laboratories, Hercules, USA). QPCR reaction components for the SYBR Green detection approach were as follows: $10 \mu \mathrm{l}$ of SYBR Green Supermix (Applied Biosystems, USA), $500 \mathrm{nM}$ each primer, and $1 \mu \mathrm{l}$ of extracted DNA, and the volume was brought to $20 \mu \mathrm{l}$ by nuclease-free water. Thermal cycling started by a first denaturation step of $10 \mathrm{~min}$ at $95{ }^{\circ} \mathrm{C}$, followed by 35 cycles of 95 ${ }^{\circ} \mathrm{C}$ for $30 \mathrm{~s}, 55^{\circ} \mathrm{C}$ for $30 \mathrm{~s}$ and $72{ }^{\circ} \mathrm{C}$ for $30 \mathrm{~s}$.

\section{Standard curve}

Five-fold serial dilutions of control genomic DNA were prepared at $90,10,1,0.1$, and $0.01 \mathrm{ng}$ to construct the calibration curve on each plate. Linear amplification down to the last dilution point representing $0.01 \mathrm{ng}$ of target DNA was obtained in each experiment (equation: efficiency $=10(-1 /$ slope $)-1$ ), and all correlation coefficients $\left(\mathrm{R}^{2}\right)$ were 0.99 to 1.00 . Melt curve analysis were also performed to check the generation of specific PCR product. A negative control (without template) was performed on each plate. All samples were performed in duplicate, and the mean values were used for quantification. The machine-generated $\mathrm{Ct}$ values and amplification plots were used to create a standard curve, which was employed to quantify the DNA content in the samples (Figure 1b).

\section{Statistical analysis}

Data were summarised as mean $\pm \mathrm{SE}$ (standard error of the mean). Groups were compared by a two-factor analysis of variance (ANOVA), and the significance of mean difference within and between the groups was done by Tukey's HSD (honestly significant difference) post hoc test after ascertaining normality by Shapiro-Wilk's test and homogeneity of variance between groups by Levene's test. Pearson correlation analysis was done to assess the association between the methods. Receiver operating characteristic (ROC) curve analysis assessed two methods' diagnostic accuracy (sensitivity and specificity) in discriminating controls and cases. A two-tailed $(\alpha=2) \mathrm{P}<0.05$ was considered statistically significant. Analyses were performed on SPSS software (Windows version 22.0). 


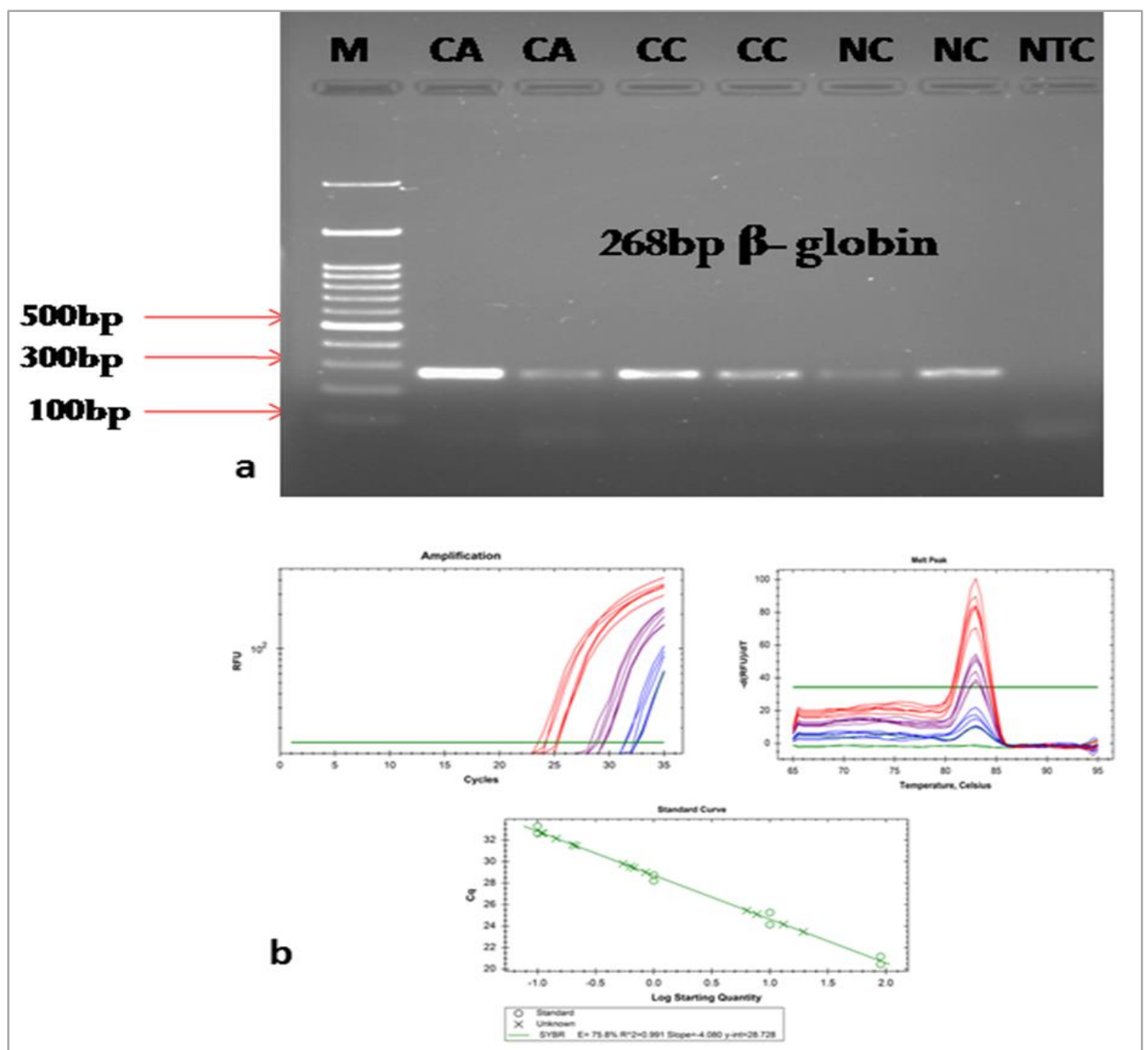

Figure 1 a: Agarose gel electrophoresis for Semi-quantitative conventional PCR: showing amplified product of $\beta$ globin gene. Where, M100 bp DNA ladder, CA-Gall bladder Carcinoma, CC- Cholecystitis, NC- Normal control \& NTC= No template control 1b: Real time amplification of cfDNA in three groups by quantitative real time PCR.

\section{Results}

The present clinical study compares cfDNA quantification by semi-quantitative (conventional PCR) and quantitative (real-time PCR) methods in gallbladder cancer patients, cholecystitis as disease control, and normal healthy individuals.

Serum cfDNA levels by Semi-Quantitative conventional PCR: CfDNA level was quantified in conventional PCR through $\beta$ globin gene amplification, and the intensity of amplified products was measured. The value of cfDNA levels in GBC, cholecystitis and control were ranged from 58.98-279.94, 73.76- 304.52, and 32.21- 114.80, respectively.

Serum cfDNA quantification by Quantitative real-time PCR: CfDNA concentration was also quantified by quantitative real-time PCR through the $\beta$-globin gene as the amplifying target. The value of cfDNA levels in GBC, cholecystitis and control were ranged from 283.94- 3848.41 ng/ml, 5.87-372.92, and 8.75 - $218.55 \mathrm{ng} / \mathrm{ml}$, respectively (Table 1). Linearity of product amplification in QPCR assessed as the slope and correlation coefficient $\left(\mathrm{R}^{2}\right)$ of the standard curve were -3.20 and $\mathrm{R}^{2}=1.00-0.99$.

\section{Mean difference in cfDNA level by two methods}

The cfDNA level of two methods (conventional and real-time PCR) and three groups (control, cholecystitis, and cancer) is summarised in Table 1. Between methods, the mean cfDNA was higher in conventional PCR than real-time PCR in the control group, whereas in both cholecystitis and cancer groups, it was higher in real-time PCR than conventional PCR. Similarly, within methods, in conventional PCR, the mean cfDNA showed a marked overlap between chronic cholecystitis and cancer, whereas in realtime PCR higher value in GBC was observed with a lower value in cholecystitis and lowest cf DNA levels in healthy controls.

For each group, comparing the difference in mean cfDNA between the two methods, the Turkey test showed similar ( $\mathrm{P}>$ 0.05) cfDNA between the two methods in both control and cholecystitis groups, i.e., did not differ significantly (Table 1 and Figure 2 (a-c). However, it was found significantly $(\mathrm{P}<0.001)$ different and higher in real-time PCR than conventional PCR in the cancer group.

Similarly, for each method, comparing the difference in mean cfDNA level between the groups, the Turkey test showed a similar $(\mathrm{P}>0.05)$ cfDNA level between all the three groups in conventional PCR (Table 2 and Figure 2 (d-e). However, in realtime PCR, it was found significantly $(\mathrm{P}<0.001)$ different and higher in the cancer group as compared to both control and cholecystitis groups but found similar $(\mathrm{P}>0.05)$ between the control group and cholecystitis group.

\section{Correlation of cfDNA quantification methods}

To find out whether two methods assesses similar cfDNA values, the Pearson correlation analysis of cfDNA values was done between two methods in all three groups and summarised in Table 3 and also shown in figure 3. The Pearson correlation analysis did not showed a significant $(\mathrm{P}>0.05)$ correlation of cfDNA values 
between two methods in control $(\mathrm{r}=0.02, \mathrm{P}=0.937)$, cholecystitis $(\mathrm{r}=0.10, \mathrm{P}=0.697)$, cancer $(\mathrm{r}=-0.08, \mathrm{P}=0.657)$ and total subjects (control + cholecystitis + cancer $)(r=0.06, P=0.622)$ indicating no perfect matching in cfDNA values obtained by the two methods.

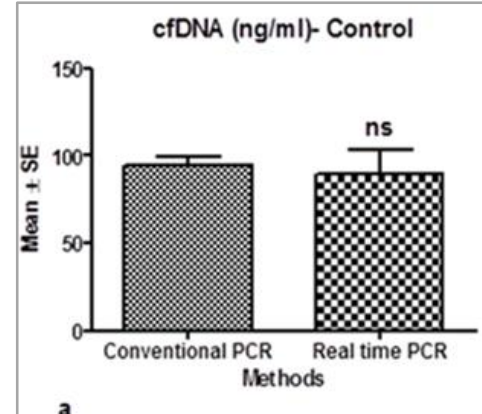

a

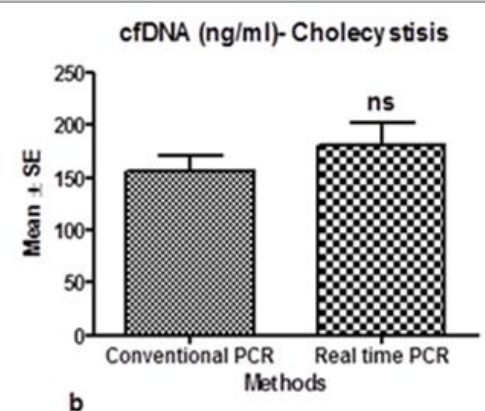

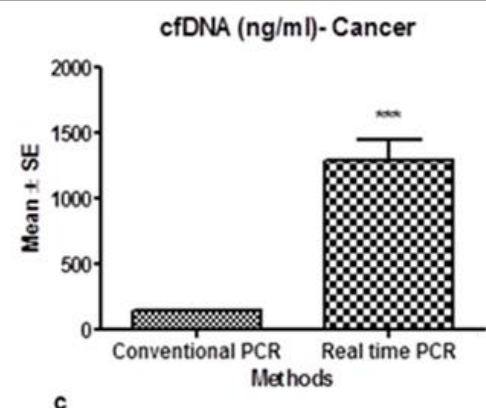

cfDNA (ng/ml)- Conventional PCR

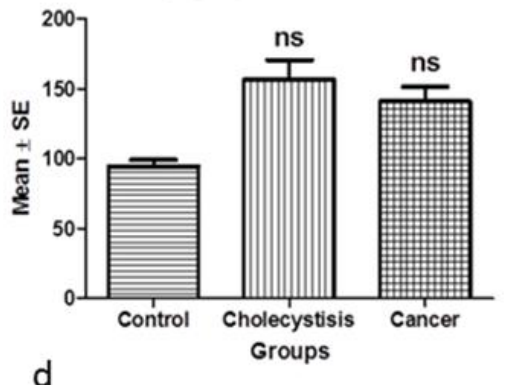

cfDNA (ng/mI)- Real timePCR

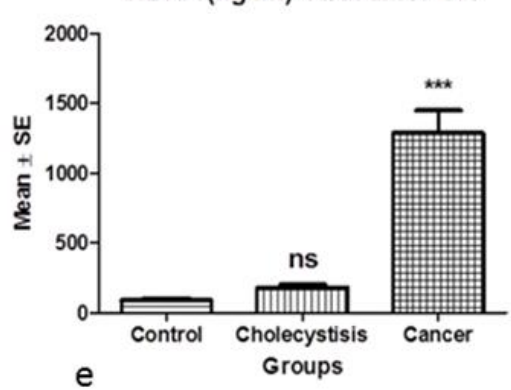

Figure 2 (a-c): Bar graphs showing comparison of difference in mean cfDNA between two methods in a) control, b) cholecystitis and c) cancer groups nsP $>0.05$ or $* * * \mathbf{P}<0.001$ - as compared to Conventional PCR

Figure 2 (d-e): d) conventional PCR and e) real time PCR methods nsP $>0.05$ or $* * * \mathbf{P}<0.001$ - as compared to Control

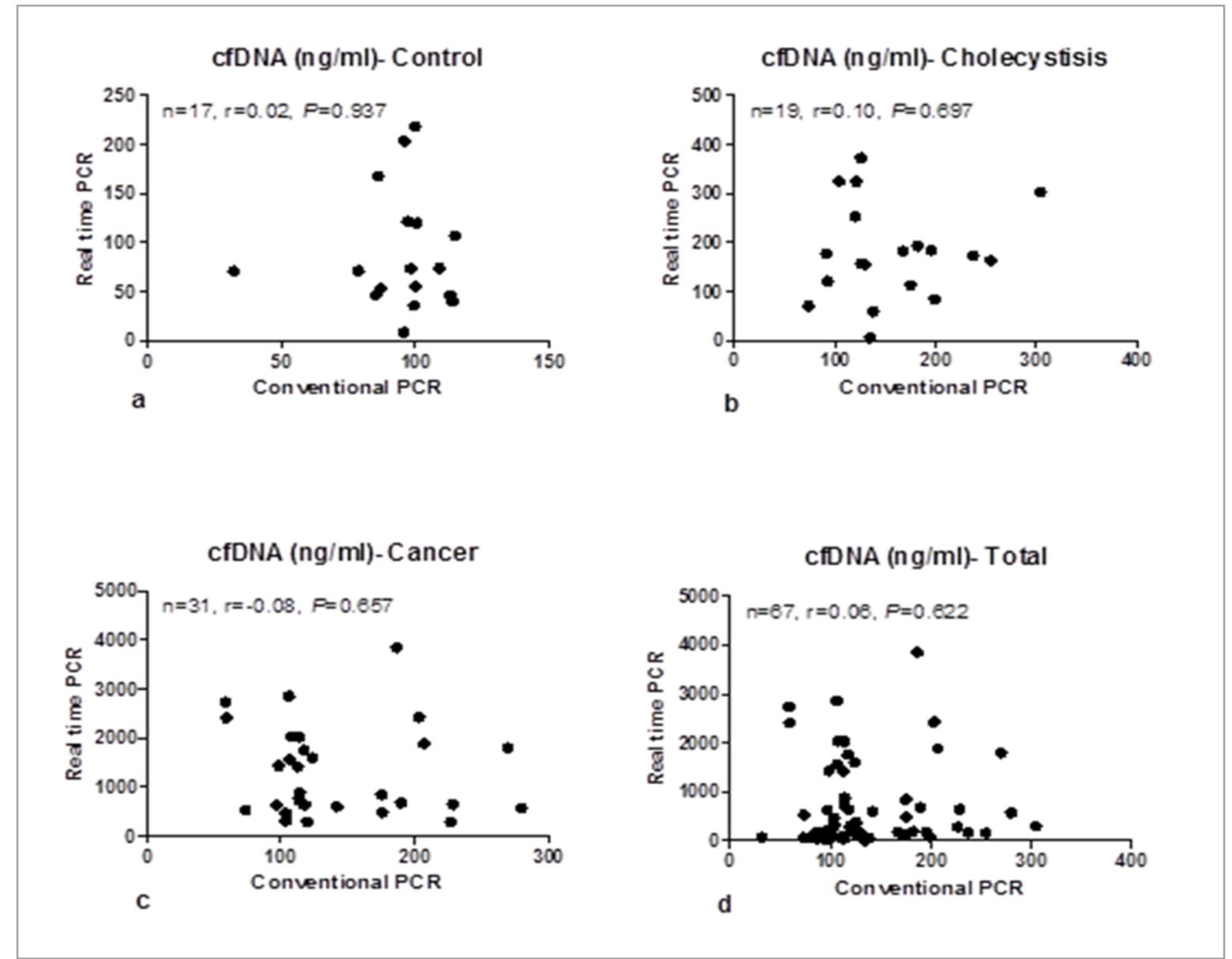

Figure 3: Pearson correlation analysis of cfDNA values between two methods in a) control, b) cholecystitis, c) cancer and d) total subjects 


\section{Diagnostic value for the method of quantifications}

\section{Conventional PCR}

The diagnostic accuracy (sensitivity and specificity) of cfDNA in conventional PCR between different groups is summarised in Table 4. The ROC curve analysis showed significant diagnostic of conventional PCR in discriminating the subjects of two groups viz. control vs. cholecystitis (AUC $=0.864, \quad \mathrm{P}<0.001$; sensitivity $=78.95 \%$ and specificity $=100.00 \%$ ), control vs. cancer $(\mathrm{AUC}=0.824, \quad \mathrm{P}<0.001 ; \quad$ sensitivity $=83.87 \% \quad$ and specificity $=76.47 \%$ ), and control vs. total cases (cholecystitis + cancer) $\quad(\mathrm{AUC}=0.839, \mathrm{P}<0.001 ;$ sensitivity $=68.00 \%$ and specificity $=94.12 \%$ ). However, the conventional PCR did not show significant diagnostic when evaluated between cholecystitis vs. cancer patients $(\mathrm{AUC}=0.666, \mathrm{P}=0.207$; sensitivity $=61.29 \%$ and specificity $=78.95 \%)$.

\section{Real-time PCR}

The diagnostic accuracy (sensitivity and specificity) of cfDNA in real time PCR between different groups is summarised in Table 5. The ROC curve analysis showed significant diagnostic of real time PCR between all groups i.e. control vs. cholecystitis (AUC $=0.780$, $\mathrm{P}<0.001$; sensitivity $=68.42 \%$ and specificity $=82.35 \%$ ), control vs. cancer $\quad(\mathrm{AUC}=1.000, \mathrm{P}<0.001 ;$ sensitivity $=100.00 \%$ and specificity $=100.00 \%$ ), cholecystitis vs. cancer (AUC $=0.981, \mathrm{P}<$ 0.001 ; sensitivity $=90.32 \%$ and specificity $=100.00 \%$ ), and control vs. total cases (cholecystitis + cancer) $(\mathrm{AUC}=0.916, \mathrm{P}<0.001$; sensitivity $=72.00 \%$ and specificity $=100.00 \%$ ).

The diagnostic accuracy of two methods was found similar $(\mathrm{P}>0.05)$ when assessed between control vs. cholecystitis $(\mathrm{Z}=0.85, \mathrm{P}=0.397)$, and control vs. total cases $(\mathrm{Z}=1.35, \mathrm{P}=$ $0.177)$. However, the diagnostic accuracy of real-time PCR was found significantly different and higher as compared to conventional PCR when assessed between control vs. cancer $(\mathrm{Z}=2.98, \mathrm{P}=0.003)$ and cholecystitis vs. cancer $(\mathrm{Z}=4.41, \mathrm{P}<$ $0.001)$.

Table 1: Comparison of cfDNA (ng/ml) between two methods and three groups

\begin{tabular}{|l|l|l|l|l|l|}
\hline Groups & $\mathbf{n}$ & Conventional PCR & Real time PCR & Mean diff & $\boldsymbol{P}$ value \\
\hline Control & 17 & $94.52 \pm 4.62$ & $89.32 \pm 14.49$ & 5.21 & 1.000 \\
\hline Cholecystitis & 19 & $156.61 \pm 13.93$ & $180.15 \pm 22.62$ & 23.55 & 1.000 \\
\hline Cancer & 31 & $140.97 \pm 10.37$ & $1284.48 \pm 162.82$ & 1143.51 & $<0.001$ \\
\hline
\end{tabular}

The cfDNA of two methods and three groups were summarised in Mean \pm SE and compared by two factor ANOVA followed by Tukey test (P value)

Table 2: For each method, comparison ( $P$ value) of difference in mean cfDNA between the groups by Tukey test

\begin{tabular}{|l|l|l|l|l|}
\hline \multirow{2}{*}{ Comparison } & Conventional PCR & Real time PCR \\
\cline { 2 - 6 } & Mean diff & $\boldsymbol{P}$ value & Mean diff & $\boldsymbol{P}$ value \\
\hline Control vs. Cholecystitis & 62.08 & 0.998 & 90.84 & 0.990 \\
\hline Control vs. Cancer & 46.45 & 0.999 & 1195.16 & $<0.001$ \\
\hline Cholecystitis vs. Cancer & 15.63 & 1.000 & 1104.33 & $<0.001$ \\
\hline
\end{tabular}

Table 3: Pearson correlation analysis of cfDNA (ng/ml) values between two methods in three groups

\begin{tabular}{|l|l|l|l|}
\hline Group & $\mathbf{n}$ & Conventional PCR vs. Real time PCR \\
\cline { 3 - 4 } & & r value & $\boldsymbol{P}$ value \\
\hline Control & 17 & 0.02 & 0.937 \\
\hline Cholecystitis & 19 & 0.10 & 0.697 \\
\hline Cancer & 31 & -0.08 & 0.657 \\
\hline Total & 67 & 0.06 & 0.622 \\
\hline
\end{tabular}

Table 4: Sensitivity and specificity of cfDNA (ng/ml) in conventional PCR between different groups using ROC curve analysis

\begin{tabular}{|l|l|l|l|l|l|}
\hline Group & Cut off value & Sensitivity (95\% CI) & Specificity (95\% CI) & AUC & $P$-value \\
\hline Control vs. Cholecystitis & $>114.81$ & $78.95(54.4-93.8)$ & $100.00(80.3-100.0)$ & 0.864 & $<0.001$ \\
\hline Control vs. Cancer & $>100.65$ & $83.87(66.3-94.5)$ & $76.47(50.1-93.0)$ & 0.824 & $<0.001$ \\
\hline Cholecystitis vs. Cancer & $\leq 119.98$ & $61.29(42.2-78.1)$ & $78.95(54.4-93.8)$ & 0.666 & 0.207 \\
\hline Control vs. Total & $>113.76$ & $68.00(53.3-80.5)$ & $94.12(71.2-99.0)$ & 0.839 & $<0.001$ \\
\hline
\end{tabular}

CI: confidence interval

Table 5: Sensitivity and specificity of cfDNA $(\mathrm{ng} / \mathrm{ml})$ in real time PCR between different groups using ROC curve analysis

\begin{tabular}{|l|l|l|l|l|l|}
\hline Group & Cut off value & Sensitivity (95\% CI) & Specificity (95\% CI) & AUC & $\boldsymbol{P}$ value \\
\hline Control vs. Cholecystitis & $>121.95$ & $68.42(43.5-87.3)$ & $82.35(56.6-96.0)$ & 0.780 & $<0.001$ \\
\hline Control vs. Cancer & $>218.55$ & $100.00(88.7-100.0)$ & $100.00(80.3-100.0)$ & 1.000 & $<0.001$ \\
\hline Cholecystitis vs. Cancer & $>372.92$ & $90.32(74.2-97.8)$ & $100.00(82.2-100.0)$ & 0.981 & $<0.001$ \\
\hline Control vs. Total & $>218.55$ & $72.00(57.5-83.8)$ & $100.00(80.3-100.0)$ & 0.916 & $<0.001$ \\
\hline
\end{tabular}

CI: confidence interval

\section{Discussion}

Liquid biopsy has emerged as a non-invasive biomarker for early detection of cancer, its progression, and treatment response. Not only the levels of cfDNA can be used to distinguish cancer patients

WwW.ijirms.in from non-cancer patients, but genomic analysis of cfDNA can also reveal known tumor mutations. Two of the most important advancements in personalized medicine, especially in the field of lung cancer, include the use of cfDNA as a diagnostic and prognostic biomarker and next-generation sequencing (NGS) for 
the mutational analysis of lung tumors. For instance, EGFR and ALK have been identified as key biomarkers in lung cancer, and molecular tests for EGFR and ALK have become common in lung cancer treatment ${ }^{[24]}$.

Circulating DNA as a biomarker is easily accessible, reliable, and reproducible and reduces the suffering and cost to society associated with the disease. CfDNA analysis in serum/plasma has proven important in diagnosing malignancy and detecting specific gene mutations. For the first time, we reported cfDNA in GBC and observed an 8-fold higher cfDNA level in the serum of GBC patients compared to normal control and 3-fold higher compared to cholecystitis using the real-time PCR method ${ }^{[22]}$. To use cfDNA as a diagnostic biomarker in various malignancies, a standardized and sensitive cost-effective technique for cfDNA assessment is needed. Several variables exist in quantifying cfDNA, including blood sampling (plasma or serum), time to the processing, and sample quality, including duration and storage temperature. Method of blood sampling, processing, and sample type (plasma or serum) has been accounted to affect the results of the cfDNA concentration. A study by Gormally et al. (2007) reported the impact of a heterogeneous sampling procedure on measurement outcome in plasma of patients collected from 23 different centres ${ }^{[2]}$. However, importance has now been placed on creating a universally acceptable cfDNA isolation and quantification protocol, especially in prenatal diagnostics and in the field of clinical practice ${ }^{[25,26]}$. Each commercial DNA extraction captures and recovers only a specific size range of DNA, typically genomic-sized or low-molecular-weight DNA. Such biased results may affect the outcome case and control studies where the cases and the controls may have differential cfDNA size profiles. Heterogeneity between the studies may be attributed to different isolation and quantification protocols, and this difference in the cfDNA yield can be up to $50 \%$. This difference is more remarkable when using silica-gel columns as small DNA fragments $(<100 \mathrm{bp})$ are loosed during isolation. The use of an isolation kit that captures all DNA fragments is of importance for the reliability of all downstream experiments, espe $\neg$ cially when the small DNA fractions $(<100 \mathrm{bp})$ are considered the most informative as they rep $\neg$ resent characteristic qualitative changes in the primary tumor such as mutations ${ }^{[24]}$.

There are various techniques for quantification of cfDNA level, with their advantages and disadvantages ${ }^{[23]}$. In the middle of various available methods, real-time PCR is being most widely used for cfDNA quantification. However, this technique requires a more trained person for handling and data analysis. Considering this, we have measured cfDNA level in serum by semi-quantitative conventional PCR and compared the results with quantitative realtime PCR. CfDNA isolated from serum was measured by amplification of the $\beta$-globin gene in real-time and conventional PCR. Our quantitative PCR results were concordant with data published by other authors ${ }^{[7,12]}$. In a recent development using the magnetic bead-based kit, the Cobas EGFR mutations Test v2 was approved in 2016 by the FDA and the European Medicines Agency (EMA) in NSCLC patients ${ }^{[27,28]}$. The separation of cfDNA with magnetic bead separation using the specific ChargeSwitch ${ }^{\circledR}$ gDNA $1 \mathrm{ml}$ Serum kit for cfDNA gave a high standardized yield in cases and controls in our study.

In our study, cfDNA levels measured by of quantitative method are concordant with the data reported by other authors who used the qPCR method for cfDNA quantification ${ }^{[29]}$. Significantly, the serum cfDNA concentration measured in cancer cases by quantitative real-time PCR was several-fold higher than the serum cfDNA amount measured by semi-quantitative conventional PCR.
The real-time PCR uses the DNA binding dye (SYBR green), detecting nearly all DNA fragments regardless of apoptotic or necrotic origin as apoptosis may result in smaller DNA fragments than necrotic DNA. CfDNA arising from tumors occurs due to necrosis and apoptosis of tumor cells. In lung cancer, a study by Sozzi et al. compared the colorimetric and quantitative real-time PCR of the human telomerase reverse transcriptase (hTERT) gene and reported the mean DNA concentration of $318 \mathrm{ng} / \mathrm{ml}$ using a colorimetric assay, but only $24 \mathrm{ng} / \mathrm{ml}$, when quantitative real-time PCR ${ }^{[29]}$. In our study, the semi-quantitative method did not correlate with SYBR Green-based quantitative real-time PCR, as depicted in table 3 and figure 3. A study by Chiminqgi et al. compared the PicoGreen method and qPCR by using b-globin and cyclophilin gene and observed that the PicoGreen method correlated well with qPCR of b-globin $(\mathrm{r}=0.81, \mathrm{P}<0.0001)$ and cyclophilin gene $(r=0.915, \mathrm{P}<0.0001)$ to discriminate between the cancer cases and normal healthy controls ${ }^{[30]}$.

Interestingly in our study, the between-group comparison of the two methods reveals no significant difference in cfDNA level of control vs. cholecystitis ( $\mathrm{p}=0.990)$. However, in cancer cases, the cfDNA level was significantly higher in real-time PCR than conventional PCR $(\mathrm{p}=<0.001)$. Further, the comparison of cfDNA level between control vs. cancer and cholecystitis vs. cancer reveals a significant difference in two of the methods used $(\mathrm{p}=<0.001)$.

We have calculated the sensitivity and specificity of cfDNA levels by the two methods between the control vs. cholecystitis, control vs. cancer, cholecystitis vs. cancer, and control vs. total (i.e., cancer cases+ disease control (cholecystitis). We have found the semi quantitative method as more sensitive and specific in discrimination of the control vs. cholecystitis than the quantitative method (78.95 \&100.0\% vs. $68.42 \& 82.35 \%$ respectively) at a cut-off point of $>114.81 \&>121.95$. In control discrimination from cancer cases, the quantitative method showed $100.0 \%$ sensitivity and specificity compared to the semi-quantitative method (sensitivity $83.87 \%$, specificity $76.47 \%$ ). However; in our study, diagnostic sensitivity and specificity were higher for quantitative real-time PCR for the discrimination of control vs. cancer, cholecystitis vs. cancer, and control vs. total

The current study is limited by smaller sample size and is single centred. A large scale study is needed to determine whether quantitative detection of serum cfDNA might increase the reliability of USG/CT/MRI findings for early detection of gallbladder malignancy. The patients with cholecystitis have higher cfDNA compared to normal, but have significantly low cfDNA when compared to GBC, therefore a patient undergoing treatment for cholecystitis may be followed up for cfDNA levels as higher levels are indicative of its progression towards cancer. The existing data suggest that the diagnostic utility of cfDNA should be assessed in large prospective trials. The same effort can be directed towards the analysis of tumor-specific genetic alterations and DNA integrity in cfDNA, to address early disease detection issues, treatment response, and to select the option of personalized therapies.

\section{Conclusion}

In conclusion, the quantitative real-time PCR method is of high accuracy, reproducibility, and time-effectiveness. Subsequently, it is regarded as a gold standard method currently available for cfDNA quantification. Also, the automated performance of the PCR setup is recommended due to the high sensitivity of the 
method, which makes it an expensive technique and requires expertise in data analysis and interpretation.

\section{Ethics approval and consent to participate}

The study was approved by the Institutional Ethics committee of Dr. Ram Manohar Lohia Institute of Medical Sciences, Lucknow and a written informed consent was obtained from the study participants.

\section{List of abbreviations}

ANOVA: Analysis of variance

CfDNA: circulating free DNA

GBC: Gallbladder cancer

hTERT: Human telomerase reverse transcriptase

PCR: Polymerase chain reaction

ROC: Receiver operating characteristic

\section{Data Availability}

The data will be available on request from the corresponding author.

\section{Conflicts of Interest}

No conflict of interest to declare.

\section{Funding Statement}

No funding was received in the current research work.

\section{Authors' contributions}

Swati Kumari (SK), Sridhar Mishra (SM), Akash Agarwal (AA), Anshuman Pandey (AP), Abhinav Arun Sonkar (AAS), Nuzhat Husain (NH)

NH: Study Conception and/or Design

SK, SM: Data Processing, Collection, Perform Experiment

NH, SK, SM: Analysis and Interpretation of Results

NH, SK: Draft Manuscript Preparation, Visualization

NH: Critical Revision or Editing of the Article

NH: Supervision, Funding Acquisition

AA, AP, AAS: Provided Clinical samples

Note: All authors read and approved the final manuscript.

\section{References}

[1] Elshimali YI, Khaddour H, Sarkissyan M, Wu Y, and Vadgama JV: The clinical utilization of circulating cell free DNA (CCFDNA) in blood of cancer patients. Int $\mathrm{j}$ mol sci. 2013, 18925-58. 10.3390/ijms140918925

[2] Gormally E, Caboux E, Vineis P, Hainaut P: Circulating free DNA in plasma or serum as biomarker of carcinogenesis: practical aspects and biological significance. Mutat Res. 2007, 635:105-17. 10.1016/j.mrrev.2006.11.002

[3] Holdenrieder S, Nagel D, Schalhorn A, et al.: Clinical relevance of circulating nucleosomes in cancer. Ann NY Acad of Sci. 2008, 1137:180-9. 10.1196/annals.1448.012

[4] Su YH, Wang M, Brenner DE, Norton PA, Block TM: Detection of mutated K-ras DNA in urine, plasma, and serum of patients with colorectal carcinoma or adenomatous polyps. Ann NY Acad Sci. 2008; 1137:197. 10.1196/annals.1448.027

[5] Diehl F, Li M, Dressman D, et al.: Detection and quantification of mutations in the plasma of patients with colorectal tumors. Proc Natl Acad Sci USA. 2005, 102:16368-73. 10.1073/pnas.0507904102

[6] Stroun M, Lyautey J, Lederrey C, Olson-Sand A, Anker $\mathrm{P}$ : About the possible origin and mechanism of circulating DNA: Apoptosis and active DNA release. Clin Chim Acta. 2001, 313:139-42. 10.1016/s00098981(01)00665-9

[7] Sozzi G, Conte D, Mariani L, et al.: Analysis of circulating tumor DNA in plasma at diagnosis and during follow-up of lung cancer patients. Cancer Res. 2001, 61:4675-8.

[8] Gal S, Fidler C, Lo YM, et al.: Quantitation of circulating DNA in the serum of breast cancer patients by real-time PCR. Br J Cancer. 2004, 1211-5. doi: 10.1038/sj.bjc.6601609

[9] Ellinger J, El Kassem N, Heukamp LC, et al.: Hypermethylation of cell-free serum DNA indicates worse outcome in patients with bladder cancer. J Urol. 2008, 179:346-52. 10.1016/j.juro.2007.08.091

[10] Altimari A, Grigioni AD, Benedettini E, et al.: Diagnostic role of circulating free plasma DNA detection in patients with localized prostate cancer. Am J Clin Pathol. 2008, 129:756-62. 10.1309/DBPX1MFNDDJBW1FL

[11] Sai S, Ichikawa D, Tomita H, et al.: Quantification of plasma cell-free DNA in patients with gastric cancer. Anticancer Res. 2007, 27:2747-51.

[12] Umetani N, Kim J, Hiramatsu S, et al.: Increased integrity of free circulating DNA in sera of patients with colorectal or periampullary cancer: direct quantitative PCR for ALU repeats. Clinical Chem. 2006, 52:1062-9. 10.1373/clinchem.2006.068577

[13] Trejo-Becerril C, Pérez-Cárdenas E, Treviño-Cuevas H, et al.: Circulating nucleosomes and response to chemotherapy: an in vitro, in vivo and clinical study on cervical cancer patients. Int J Cancer. 2003, 104:663-8. 10.1002/ijc. 11003

[14] $\mathrm{Li} \mathrm{B}, \mathrm{Pu} \mathrm{K}, \mathrm{Ge} \mathrm{L}, \mathrm{Wu} \mathrm{X}$ : Diagnostic significance assessment of the circulating cell-free DNA in ovarian cancer: An updated meta-analysis. Gene. 2019, 714:143993. 10.1016/j.gene.2019.143993

[15] Ellinger J, Wittkamp V, Albers P, et al.: Cell-free circulating DNA: diagnostic value in patients with testicular germ cell cancer. J Urol. 2009, 181:363-71. 10.1016/j.juro.2008.08.118

[16] Chen K, Zhang H, Zhang LN, et al.: Value of circulating cell-free DNA in diagnosis of hepatocelluar carcinoma. World J Gastroenterol. 2013, 19:3143. 10.3748/wjg.v19.i20.3143

[17] Fong SL, Zhang JT, Lim CK, Eu KW, Liu Y: Comparison of 7 methods for extracting cell-free DNA from serum samples of colorectal cancer patients. Clin Chem. 2009, 55:587-9. 10.1373/clinchem.2008.110122.

[18] Zaher ER, Anwar MM, Kohail HM, El-Zoghby SM, Abo-El-Eneen MS: Value of circulating DNA concentration and integrity as a screening test for detection of cancer in an Egyptian cohort. Alexandria $\mathbf{J}$ Med. 2012, 48:187-96. 10.1016/j.ajme.2012.03.003 
[19] Shapiro B, Chakrabarty M, Cohn EM, Leon SA: Determination of circulating DNA levels in patients with benign or malignant gastrointestinal disease. Cancer, 1983, 51:2116-20. 10.1002/1097-0142(19830601)51:11

[20] Fournié GJ, Courtin JP, Laval F, et al.: Plasma DNA as a marker of cancerous cell death. Investigations in patients suffering from lung cancer and in nude mice bearing human tumours. Cancer lett. 1995, 91:221-7. 10.1016/0304-3835(95)03742-f

[21] Stroun M, Anker P, Maurice P, Lyautey J, Lederrey C, Beljanski M: Neoplastic characteristics of the DNA found in the plasma of cancer patients. Oncology. 1989, 46:318-22. 10.1159/000226740.

[22] Kumari S, Tewari S, Husain N, Agarwal A, Pandey A, Singhal A, Lohani M: Quantification of circulating free DNA as a diagnostic marker in gall bladder cancer. Pathol Oncol Res. 2017, 23:91-7. 10.1007/s12253-0160087-0

[23] Gal S, Fidler C, Lo YM, et al.: Quantitation of circulating DNA in the serum of breast cancer patients by real-time PCR. Br J cancer. 2004, 90:1211-5. 10.1038/sj.bjc.6601609

[24] Macías M, Alegre E, Alkorta-Aranburu G, et al.: The dynamic use of EGFR mutation analysis in cell-free DNA as a follow-up biomarker during different treatment lines in non-small-cell lung cancer patients. Dis markers. 2019: 7954921. 10.1155/2019/7954921

[25] Butt AN, Swaminathan R: Overview of circulating nucleic acids in plasma/serum: update on potential prognostic and diagnostic value in diseases excluding fetal medicine and oncology. Ann NY Acad Sci. 2008; 1137:236-42. 10.1196/annals.1448.002

[26] Wagner J: Free DNA-new potential analyte in clinical laboratory diagnostics? Biochem med. 2012, 22:24-38. 10.11613/bm.2012.004

[27] Kwapisz D: The first liquid biopsy test approved. Is it a new era of mutation testing for non-small cell lung cancer? Ann Transl Med. 2017, 5: 46. 10.21037/atm.2017.01.32

[28] Herrera LJ, Raja S, Gooding WE, El-Hefnawy T, Kelly L, Luketich JD, Godfrey TE: Quantitative analysis of circulating plasma DNA as a tumor marker in thoracic malignancies. Clin Chem. 2005, 51:113-8. 10.1373/clinchem.2004.039263

[29] Sozzi G, Conte D, Leon M, et al.: Quantification of free circulating DNA as a diagnostic marker in lung cancer. J Clin Oncol. 2003, 21:3902-8. 10.1200/JCO.2003.02.006

[30] Chiminqgi M, Moutereau S, Pernet P, et al.: Specific real-time PCR vs. fluorescent dyes for serum free DNA quantification. Clin Chem Med Lab. 2007, 993-995. 10.1515/CCLM.2007.191

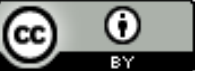

Open Access This article is licensed under a Creative Commons Attribution 4.0 International License, which permits use, sharing, adaptation, distribution and reproduction in any medium or format, as long as you give appropriate credit to the original author(s) and the source, provide a link to the Creative Commons license, and indicate if changes were made. The images or other third party material in this article are included in the article's Creative Commons license, unless indicated otherwise in a credit line to the material. If material is not included in the article's Creative Commons license and your intended use is not permitted by statutory regulation or exceeds the permitted use, you will need to obtain permission directly from the copyright holder. To view a copy of this license, visit https://creativecommons.org/licenses/by/4.0/.

(C) The Author(s) 2021 